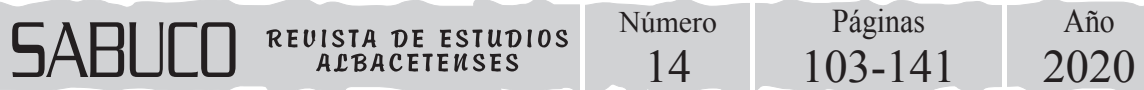

\section{UNA APROXIMACIÓN A LA HISTORIA DE LA CIENCIA EN LA PROVINCIA DE ALBACETE}

\section{AN APPROACH TO THE SCIENCE HISTORY IN ALBACETE PROVINCE}

\author{
Por \\ Alonso VERDE*,1,2 \\ Dolores MORENO ${ }^{1}$ \\ Domingo BLANCO ${ }^{1,3}$ \\ Miguel LUCAS ${ }^{1}$
}

Recibido: 10 de octubre de 2020

Aprobado: 30 de diciembre de 2020

\footnotetext{
${ }^{1}$ Instituto de Estudios Albacetenses "Don Juan Manuel"

${ }^{2}$ Sociedad de Etnobiología

${ }^{3}$ Sociedad Albacetense de Ornitología

*alonsoverde@gmail.com

Cómo citar este artículo:

Verde, A., Moreno, D., Blanco, D., Lucas, M. (2020). Una aproximación a la historia de la ciencia en la provincia de Albacete. Sabuco, 14: 103-141

http://doi.org/10.37927/sabuco.14_5
} 



\section{RESUMEN}

La provincia de Albacete es un territorio de reciente creación, una tierra de encrucijada, cuyos núcleos de población más importantes apenas han ejercido a lo largo de la historia como lugares con influencia en la producción de conocimiento. Sin embargo, sí que encontramos a personajes, nacidos o establecidos en la provincia, que en un momento dado han dejado su huella en diversos campos y disciplinas de las ciencias. A través de un proceso de revisión bibliográfica histórica, geográfica y biográfica se ha recopilado información de hasta veintisiete autores de reconocido prestigio, tanto a escala nacional como internacional, en sus respectivos campos científicos. A mediados del siglo XVI encontramos en Alcaraz, importante centro económico, cultural y de conocimiento por aquella época, al primero de nuestros personajes estudiados: el Bachiller Sabuco. Durante los siglos XVIII y XIX, la corriente de desarrollo tecnológico que corría por Europa también se ve reflejada en estas tierras. En este período fue clave la creación del Instituto de Enseñanza Secundaria en Albacete y de la Escuela Normal, lo que facilitó el acceso a los estudios a un mayor número de personas. Es en el siglo XX, coincidiendo con la gran revolución científica que tuvo lugar después de la Segunda Guerra Mundial, cuando encontramos a la mayoría de estos personajes, que se incorporan a las nuevas disciplinas científicas como son: la física, la química, la geología, la biología, la pedagogía o incluso la economía trabajada desde una perspectiva medioambiental.

Palabras clave: biografía de científicos, historia de la ciencia, Albacete provincia.

\section{ABSTRACT}

The province of Albacete as we know it today is a recently created territory, a crossroads lands, whose most important population centers, have hardly influenced on knowledge. A remarkable investigation has been made about people deceased, born or settled in the province, who have put its stamp on any of the fields of science, ranging from medici- 
ne, mathematics, and pharmacy, to pedagogy, or architecture, throughout different periods of history. Through a process of historical, geographical, and biographical bibliographic review, information about up to 27 nationally and internationally-recognized authors in different fields has been compiled. These characters are the ones who have really built up the history of science in the province of Albacete. At the beginning of the 16th century, Renaissance period in which Bachiller Sabuco stands out, we can find the first one, original from the city of Alcaraz, which was an important economic, cultural, and knowledge center. During the 18th and 19th centuries, the technological development running through Europe is also reflected in these lands. Besides, the creation of the Institute of Secondary Education in Albacete and Scholl of Teaching which facilitated wider access to education, was fundamental then. Finally, in the $\mathrm{X}$ century, coinciding with the great scientific revolution that took place after World War II, we can find the majority of personalities, who study new disciplines incorporated into the world of science, such as Physics, Chemistry, Geology, Biology, Pedagogy, or even Economy worked from an environmental perspective.

Keywords: biography of scientists, history of science, Albacete province.

\section{INTRODUCCIÓN}

El reconocimiento de ciertos personajes que han sobresalido a lo largo de la historia en el mundo de las humanidades y de las artes es frecuente. Sin embargo, esa percepción cambia si el área de estudio corresponde a lo que, quizás erróneamente, se entiende por «ciencias». Ya sabemos que la clasificación de las disciplinas científicas obedece a presupuestos epistemológicos muy diversos y cambiantes con el tiempo, siendo quizás la división entre ciencias sociales y ciencias naturales la que más polémica ha generado. Sin entrar en este debate, nos interesa para este análisis solamente el campo de las ciencias desde su perspectiva histórica. Seguimos el criterio del profesor López Piñero cuando dice que «la historia de la ciencia es, simplemente, una disciplina historiográfica especia- 
lizada, es decir, una de las vertientes del «saber histórico» que se inserta dentro de un proyecto como el planteado por P. Vilar en su concepción de «historia total» (López-Piñero, 1979). La nueva corriente historiográfica de la Escuela de Annales, que comienza a partir de 1929 con L. Febvre, M. Bloch y continuada por F. Braudel, integra otras disciplinas sociales para el conocimiento del pasado. Su punto de partida es que el hecho histórico no puede fragmentarse y proponen, como después haría P. Vilar (1964), una visión total del pasado, donde la historia de la ciencia es un pilar fundamental.

En el trabajo que presentamos se pretende dar a conocer a personajes del mundo de las ciencias que, debido a sus temas de estudio, son menos reconocidos. En la relación solo hemos tenido en cuenta a los personajes ya fallecidos, nacidos en cualquier municipio de la provincia o bien a aquellos estrechamente relacionados con alguna de sus localidades y que han desarrollado un papel destacado en cualquier campo científico (medicina, botánica, matemáticas, física, química, geología, arquitectura, ingeniería, veterinaria, etc.), sin incorporar a los de humanidades, que ya han sido objeto de estudios más prolijos. No obstante, asociar a un territorio específico, como es el caso de Albacete, unas determinadas disciplinas científicas junto con sus protagonistas, precisa algunas aclaraciones sobre los conceptos de territorialidad y cientificidad, que manejaremos en este estudio.

\subsection{Ciencia y territorio}

La búsqueda del conocimiento ha sido siempre el punto de partida de la existencia del ser humano, el que le ha llevado a evolucionar y a perpetuarse como especie. Explorar el entorno natural con el fin de utilizar todos los recursos que este le proporciona: alimento, medicina, cobijo, ropa, herramientas, combustible, etc., ha sido una tarea que le ha acompañado desde su origen. Al fin y al cabo, esta capacidad de observación inherente al propio ser humano, así como la de experimentar y retener en la memoria información para luego contarla y transmitirla, no se aleja mucho de lo que en el mundo de la ciencia se conoce como «método científico». 
Desde que Kuhn publicara en 1962 La estructura de las revoluciones científicas, la presencia de la historia va a acompañar siempre a la noción de «ciencia» que, en cada período, se sustenta con los paradigmas aceptados y reconocidos por la comunidad. Desde un punto de vista diacrónico, que es el mantenido en este trabajo, los científicos de cada etapa histórica explican la naturaleza y su entorno mediante el conjunto de leyes, conceptos y teorías dominantes en cada momento hasta que se produce una crisis y el consiguiente cambio de paradigma (Kuhn, 1992).

En el recorrido realizado dejamos aparte la antigüedad e iniciamos la andadura con las consecuencias de las escuelas científicas en el mundo árabe, y especialmente en el Al-Ándalus, donde estaba incluida nuestra provincia, que ya contemplaban las especializaciones en los diferentes campos científicos (agrónomos, médicos, matemáticos, físicos, astrónomos o geógrafos, entre otros especialistas). En el siglo XVI, Galileo Galilei da un paso importante en la historia de la ciencia, incorporando la observación, la hipótesis y la experimentación a sus estudios (Gargantilla, 2019); aunque es Francis Bacon (1561-1626) con su obra Novum Organum quien refuerza la renovación y defensa del método científico. Este es un período en el que aún conviven teólogos, filósofos y gramáticos con los nuevos científicos de la naturaleza, quienes tienen por modelo de hombre al humanista. Los progresos tecnológicos producidos a partir del siglo XVII y las nuevas ideas de la Ilustración, como una nueva etapa del pensamiento moderno, explican el mundo mediante los términos de causa y efecto y suponen el triunfo, al final, del paradigma positivista que entiende las ciencias como teorías neutrales, verdaderas y válidas universalmente. El desarrollo de las matemáticas y la revolución industrial, con sus descubrimientos científicos, dominan los siglos XIX y XX hasta la aparición de lo que se ha venido a llamar «posmodernidad». En cada momento, y como producto del contexto cultural-científico, se desarrollan las disciplinas y campos de estudio a los que se van a dedicar nuestros personajes.

Se trata de científicos que viven en un espacio culturizado y ordenado según las premisas políticas de cada momento. Este territorio constituye la base espacial donde tienen lugar las relaciones humanas que le otorgan sentido y donde se refleja la acción recíproca entre hombre y medio. Sin embargo, como nos aclara el antropólogo J. L. García, la vida de una 
comunidad va más allá de los límites territoriales donde se desenvuelve (García, 1976), es decir, muchas veces no coincide el espacio geográfico delimitado políticamente por algunos de sus actores, con otras realidades y sistemas de vida, tal y como ocurre, por ejemplo, con el nomadismo u otras movilidades humanas. Esta idea es importante para nuestro análisis ya que en el caso de Albacete, a pesar de la ausencia, como veremos, de centros de producción científica o cultural, han tenido presencia actividades y personas relacionadas con el mundo de las tecnologías y de las ciencias.

La Meseta Sur, donde se asienta Albacete, es un espacio con unas determinadas condiciones geográficas y de biodiversidad que los vaivenes de la historia han culturizado de forma exclusiva, aunque quizás no tanto como para otorgarle una identidad territorial, algo que sí encontramos en otros lugares de forma mucho más definida. Sus fronteras han sido, por ello, muy moldeables y en cada momento histórico encontraremos deslizamientos hacia los cuatro puntos cardinales, según los intereses y estrategias de los poderes políticos.

La provincia de Albacete es una construcción política reciente, nacida de la ordenación administrativa de Javier de Burgos en 1833, y se configura mediante la suma de espacios territoriales pertenecientes anteriormente a otros entes con más o menos sentido geográfico, histórico o cultural. Los territorios de la Submeseta Meridional han pertenecido desde la Reconquista a la Corona de Castilla, pero la peculiar repoblación medieval y la posterior evolución de la monarquía hispana, en lo que a la planificación territorial se refiere, hace que las demarcaciones de rango menor hayan sido cambiantes y casi siempre muy desarticuladas. Los intentos racionalizadores que surgen a partir de los proyectos ilustrados del siglo XVIII y de las reformas liberales de la primera mitad del siglo XIX colocan a la provincia, a imitación de los departamentos franceses, como la división político-administrativa más adecuada al deseado modelo centralista. En los diferentes proyectos territoriales anteriores al de 1833, como el bonapartista de 1810 de José María de Lanz y el de 1822 de Bauzá-Larramendi, se parte de criterios geográficos (cuencas fluviales), pero el mismo Larramendi trabaja en 1829 en una demarcación que conserva los límites históricos más arraigados (Burgueño, 2014) y que prácti- 
camente es la misma de Javier de Burgos. En estas divisiones no se tuvo en cuenta el hecho cultural nacido de la simbiosis diacrónica de la relación entre los espacios y la acción humana por lo que siempre han parecido cartografías de despacho y artificiosas.

En su devenir histórico el actual territorio provincial albacetense ha pertenecido a la Carthaginense romana; a las taifas de Valencia, Murcia y Toledo de Al-Ándalus; a la Corona de Castilla bajo varias fórmulas de demarcación en la época medieval y Edad Moderna, y así hasta el siglo XVIII, en el que se engloba en las provincias de La Mancha, Murcia y Cuenca (Carpio, 1977). Con la división de J. de Burgos y la posterior Ley Moyano de educación (de 9 de septiembre de 1857) se empieza a visualizar el mapa político de España a través de las representaciones para escolares donde las provincias van adquiriendo identidad de patrias locales. Albacete empezó a ser un lugar representado y de pertenencia a otro ente mayor, Murcia, y todo dentro del gran mapa de la piel de toro que era España. Pascual Madoz, autor del Diccionario Enciclopédico, nos advierte para mediados del siglo XIX que en Albacete no ha transcurrido el tiempo suficiente para que se genere eso que llamamos hoy en día identidad, aunque él caracteriza a los hombres de Albacete como laboriosos, obedientes, francos y festivos, entre otras cualidades (Madoz, 1987).

Efectivamente, sabemos que las identidades no son propiedades estáticas y esenciales adheridas a los pueblos desde sus más remotos orígenes, sino que obedecen a procesos o diálogos entre las semejanzas y las diferencias. La provincia de Albacete acababa de nacer por decreto cuando el político y geógrafo Pascual Madoz redactaba su conocido Diccionario, finalizado en 1850, y aún no percibía un tipo uniforme de albacetense. De los 80 pueblos con los que contaba la nueva provincia al nacer, 28 pertenecían anteriormente a Cuenca, 24 a La Mancha, 28 a Murcia y uno a Valencia, lo que ya nos indica su falta de unidad cultural (Fuster, 1981). Sin embargo, en poco tiempo, la dinámica de la Diputación Provincial con la creación de la Audiencia Territorial, las nuevas infraestructuras provinciales y obras públicas, los caminos, los centros de beneficencia y hospital, las escuelas, el nuevo Instituto de Segunda Enseñanza y Magisterio, el auge de la nueva capital, el ferrocarril, los nuevos símbolos y el cierto desarrollo económico fueron dando sentido al nuevo mapa pro- 
vincial, cotas que no alcanzaría, sin embargo, el regional murciano. Con J. de Burgos desaparecía la provincia de la Mancha, nacería Albacete y se ordenarían las provincias en los entes territoriales regionales de Castilla la Nueva y Murcia.

\section{MATERIAL Y MÉTODOS}

Para desarrollar este trabajo hemos recurrido a la búsqueda y exploración de, por una parte, información biográfica de personajes ilustres que a lo largo de la historia han desarrollado un papel importante en cualquiera de los campos de la ciencia; y por otra, de trabajos sobre historia y geografía de la provincia de Albacete.

Esta labor ha sido doble: por un lado, revisión de fuentes bibliográficas y, por otro, búsquedas en internet, en todos los casos apuntando a una lectura crítica y a una evaluación objetiva de estos documentos o fuentes. Se establecieron unos criterios de inclusión o exclusión, como que estos personajes estuvieran fallecidos y que todos ellos fueran originarios de la provincia de Albacete o que estuvieran estrechamente relacionados con esta.

\subsection{Fuentes bibliográficas}

Para desarrollar el trabajo de investigación se han analizado tanto fuentes o documentos primarios como fuentes secundarias. Por un lado se han revisado trabajos monográficos sobre biografías o reseñas biográficas de personajes ilustres como son los trabajos de Almendros-Toledo (1997), Adán Oliver (2015), Baquero-Almansa (1884), Bigues et al. (2018), Cordero del Campillo (1982), Fuertes-Herreros (1981), Gómez-Peñalver (2007), Henares (1976), Hernández-Cutillas (2006 y 2014), Mateos y Sotos (1986), Mellizo (1996), Moreno-García (2011 y 2013), Moreno y Manjón (2016), Revenga (2008), Rodríguez de la Torre (1987a y 2002), entre otros; así como diccionarios biográficos, como son los trabajos de García-Serrano y González-Calero (1999) y de Díez-Barra y GonzálezCalero (2020). 
Asimismo, se han revisado trabajos sobre historia de la ciencia y del conocimiento en los territorios de la provincia de Albacete, como son las obras de Belmonte (2010) González-Calero (2016), Henares (1984), Rodríguez de la Torre (1987b), Rodríguez (2017), Prados-García (2018), López-Piñero et al, (1983), Losa y Cózar (2002), Sánchez-García (2012), Rivera (1984) y Tobarra (2019), entre otros.

Y, por último, se han revisado fuentes bibliográficas sobre historia y geografía de la provincia de Albacete que nos han servido para trabajar el contexto histórico en el que desarrollaron su labor cada uno de los autores, es el caso de los trabajos de Ayllón (2002, 2015 y 2019), Fuster (1976), Madoz (1987), Pretel (1986 y 1999) y Vila-Valentí (1989).

\subsection{Búsquedas en internet}

Las búsquedas en internet han sido fundamentales para seleccionar y localizar información de la mayoría de los personajes que han forjado la historia de la ciencia en la provincia de Albacete, entre los trabajos a los que se ha recurrido se encuentran: Burgueño (2014), Mencía-Valdenebro (2005), Real Academia de la Historia (2018a y 2018b), Gascón y Storch (2009), Tomás-Ibáñez (1993) y Wikipedia

\subsection{Selección y organización de los campos de conocimiento}

El problema que se nos planteaba para la presentación de los personajes analizados era, a la vez, de índole epistemológico, cronológico y temático, puesto que la misma historia de la ciencia es producto del contexto cultural en la que nace y se hace. La ciencia o las disciplinas científicas actuales son muy diferentes a las del pasado y en el seno de las mismas se han venido produciendo continuas génesis, ramificaciones e incorporaciones que siguen los modelos institucionalizados por el conocimiento hegemónico.

En consecuencia, hemos creído conveniente mantener los campos de conocimiento tal y como se clasificaban en cada momento histórico y la inclusión de los personajes a los mismos. Se trata de las mismas cate- 
gorías y estudios establecidos desde las universidades que, al fin y al cabo, son los proyectados desde el Estado y desde el resto de poderes. El concepto y la clasificación de las ciencias han obedecido-y obedecen- a criterios construidos socialmente en los que es difícil encontrar consensos, precisamente porque cada grupo o estamento parte de situaciones distintas o enfrentadas y porque, además, en dichos grupos, las relaciones son muy complejas. No es nuestra intención abordar aquí esta problemática, pero sí dejar constancia de los cambios de realidad y de los paradigmas científicos que vamos a encontrar para encasillar cada biografía dentro del marco cultural en el que estos personajes destacaron y desarrollaron su actividad.

\section{RESULTADOS Y DISCUSIÓN}

Resulta difícil escribir sobre la historia de la ciencia en un territorio de reciente creación ya que la provincia nace, según venimos diciendo, de una manera más o menos inventada (Burgueño, 1995). Con anterioridad a 1833 , las localidades de esta provincia con relevancia en el mundo de las ciencias pertenecían a entidades territoriales distintas. Como bien señala Rodríguez de la Torre, no es que no haya historia de la ciencia en Albacete, sino que más bien lo que no hay es historiografía de la ciencia albacetense:

«La historia de la ciencia, que trata y no excluye la biobibliografía de los científicos es, además, la historia de los saberes científicos, la historia de la actividad científica como un aspecto de la realidad histórica de un país, de una región o provincia, de una localidad. Es, también, la historia de la circulación de las ideas científicas renovadoras es, finalmente, y sobre todo, la historia ¿pequeña? de miles y miles de hechos, saberes, destrezas, polémicas, avances y retrocesos, en tantas localidades posibles y en tantas épocas determinadas (años, generaciones, siglos...)» (Rodríguez de la Torre, 1987b).

Históricamente, hasta la fundación de la Universidad de Castilla-La Mancha en 1985 y su campus de Albacete, esta provincia estuvo distanciada de los centros de conocimiento y de producción cultural. Si dejamos fuera la formación autodidacta, que la puede haber, la enseñanza de las 
ciencias y sus disciplinas es inseparable de las universidades. Alcalá de Henares, Valencia o Murcia, es decir, las sedes universitarias importantes, resultaban para las épocas premodernas bastante lejanas para cualquier albacetense que aspirase a seguir unos estudios superiores. Lo mismo ocurría con otros posibles centros de menor rango localizados en Toledo, Almagro, Sigüenza o Gandía ya que las distancias eran iguales o mayores. Así pues, solamente una pequeña élite adinerada podía permitirse realizar estudios superiores en localidades, para esas épocas, muy retiradas de su Albacete natal. Las preferencias, de los pocos que lo hacían, estaban divididas entre las universidades del centro peninsular (Madrid, Alcalá de Henares, Toledo o Salamanca) y las del Levante (Valencia y Murcia). Los cambios modernizadores de la España de los siglos XIX y XX tampoco incluyeron a Albacete como sede de posibles instituciones educativas que no fueran las de las enseñanzas medias y las escuelas normales. De los personajes analizados se puede destacar la preferencia de Madrid y Alcalá de Henares para sus estudios, seguido con distancia de Valencia, Murcia y Barcelona. Muy pocos se forman en el extranjero, excepto en los casos de emigración política, y autodidactas solo hemos encontrado un caso.

Las primeras universidades castellanas datan del siglo XIII, y las madrasas de Al-Ándalus son del siglo XIV, luego es de suponer que en época musulmana la enseñanza estaba relegada al ámbito de las mezquitas. Alfonso X, tras la conquista castellana de Murcia, fundaría a mediados del siglo XIII la madrasa dirigida por el sabio Al-Ricotí, que funcionaría como una escuela de estudios superiores donde tenían cabida cristianos, musulmanes y judíos, aunque tuvo una vida muy corta, a diferencia de la de Granada, que perduró hasta 1499 (Prados, 2018). El otro foco cultural de esta época es la Escuela de Traductores de Toledo donde eruditos de todos los rincones de Europa se concentraron, bajo el amparo del arzobispo de Toledo, no solo para la traducción de textos antiguos, sino que también se realizó una gran labor de mediación cultural entre las tres comunidades étnicas (Azaola-Piazza, 2007).

Nos ha parecido esclarecedor agrupar la biografía de nuestros personajes en tres bloques que siguen la evolución cronológica de los paradigmas científicos desde la aparición de la ciencia moderna. En primer lugar, la revolución copernicana y renacentista; en segundo lugar, la im- 
plantación del positivismo tras la Ilustración; y para finalizar, la crisis del positivismo con el surgimiento de las nuevas disciplinas del postmodernismo.

\subsection{PARADIGMA RENACENTISTA: Campo de la ciencia y del humanismo}

Entre los siglos XII y XIII los territorios albacetenses se incorporan desde las taifas musulmanas al reino de Castilla con los consiguientes cambios organizativos e institucionales. Los concejos (Alarcón, Alcaraz, Chinchilla, Almansa y Tobarra) constituyen a partir de entonces la base del emergente sistema feudal con un perfil aldeano y con escasa población (desierto castellano-manchego oriental), a excepción de las montañas sureñas. La historiografía de Albacete para esta época (Pretel, 1986 y Ayllón, 2015) nos habla de una sociedad feudal en la que es difícil imaginar la participación de algunos de los vecinos de los nuevos concejos en las instituciones universitarias arriba indicadas. Hasta bien entrado el siglo XIV no encontramos personajes con cierta formación académica, como es el caso que recoge Carlos Ayllón en la comunidad judía de Alcaraz en la que vive Samuel Bar Iom Tob que en 1380 tradujo a Maimónides (Ayllón, 2019), entre otros. Los continuos pogromos harían que este tipo de población de etnia judía y culta fuera desapareciendo de estas tierras.

Los personajes de esta época son los pioneros y aparecen en los albores de la historia de la ciencia en nuestra provincia. Humanistas de formación, abarcaban todos los campos, desde la filosofía, a la gramática y las ciencias (farmacia, medicina, física o matemáticas). Entre 1470 y los inicios de la crisis del siglo XVII se van a fundar en la península ibérica gran número de centros universitarios que cumplirán el papel de formar a la nueva burocracia real y al funcionariado eclesiástico. Además, se encargan de la prestación de algunos servicios como el de la medicina y el de la enseñanza. En total, en 1625, había 32 fundaciones universitarias, 18 en Castilla y 11 en Aragón, y todas bastante alejadas de Albacete que solo contaba con el foco cultural de Alcaraz, y quizás también en Chinchilla, donde se pueden encontrar juristas, médicos y humanistas con formación universitaria. Rodríguez de la Torre (1987b) cita para esta etapa la 
existencia del estudio general de Alcaraz, el cual ha sido poco investigado, que da cobijo a los humanistas y científicos que recogemos en este trabajo (Miguel y Oliva de Sabuco, el preceptor Abril, Toribio de Alcaraz o el humanista Bartolomé Ximénez). Para el estudioso A. Pretel «el ambiente intelectual y artístico de Alcaraz es una curiosa mezcla de elementos profanos y sagrados, antiguos y modernos, que la hacen peculiar, pueblerina $y$, al tiempo, pretenciosa» (Pretel, 1999), pero de sus estudios y los de Ayllón (2002) no se desprende la existencia de un foco cultural sólido, a pesar de los músicos, escritores, pintores, escultores y humanistas de renombre que conocemos. Citamos a continuación los más relevantes.

\subsubsection{García Sánchez, Toribio. Hernando Toribio de Alcaraz (maestro cantero)}

Alcaraz (Albacete) 1500-¿Méjico? 1575

Arquitecto y maestro cantero que se confunde con su homónimo que trabajó también en América. Su actividad la realiza en Nueva España donde construyó conventos y la catedral de Pátzcuaro. Suele aparecer con el nombre de Fray Toribio de Alcaraz, aunque no era religioso. La última documentación que ha aparecido en el actual México sobre Toribio de Alcaraz es de alrededor de 1575 y se refiere a la construcción de la iglesia y convento de Cholula. En este o en años posteriores debió de fallecer (Rodríguez de la Torre, 2010).

\subsubsection{Alcaraz, Toribio de (arquitecto)}

Alcaraz (Albacete), 1518-Charcas (Bolivia), 1573

No debe confundirse con su otro homónimo citado más arriba que también procedía de Alcaraz y trabajó en México. Edificó la portada de la Iglesia Mayor de Arequipa y colaboró en las obras de la catedral de La Plata, pero destacó por la construcción de puentes y lagunas artificiales para la minería ya que también se dedicó a la explotación de minerales y producción agraria (Rodríguez de la Torre, 2010). 


\subsubsection{Sabuco y Álvarez, Miguel (filósofo, boticario)}

Alcaraz (Albacete), 1525 -Alcaraz (Albacete), 1588

Estudió en la Universidad de Alcalá de Henares en torno al año 1542. Probablemente hizo su bachillerato en Artes y en Filosofía, en el que estudió gramática, retórica y lógica; y, sobre todo, la física (filosofía natural, cosmología y psicología), matemáticas, geografía, astronomía y metafísica. Del conocimiento de todas estas materias hace gala en su Nueva filosofía que permitiría catalogarlo entre los médicos filósofos del Renacimiento español (Henares, 1976).

No consta documentalmente que fuera médico, boticario, procurador síndico ni letrado, aunque en sus escritos demuestra poseer amplios conocimientos médicos, de anatomía, de fisiología y de historia natural, además de cultura clásica, filosofía y literatura.

La Nueva filosofía de la naturaleza del hombre (figura 2) se publicó por primera vez en Madrid, gracias a la imprenta de Pedro Madrigal, en 1587. La obra tuvo una amplia difusión y ha sido objeto de reediciones sucesivas durante cinco siglos, tanto en España como en el extranjero. Es preciso destacar la figura de Oliva Sabuco de Nantes, hija de Miguel de Sabuco. En cuanto a la autoría de la obra, los Sabuco (padre e hija, Miguel y Luisa Oliva) desde siempre han atraído la curiosidad de los investigadores.

\subsubsection{Simón Abril, Pedro (humanista)}

Alcaraz, circa 1530 - Medina de Rioseco (Valladolid), 1595

Importante personaje de la ciencia, la cultura humanística y la divulgación y didáctica científicas en el siglo XVI. Hasta hace poco se le consideraba tan solo un excelente gramático, latinista y helenista, y no gozaba de gran reconocimiento. No obstante, la importancia moderna de Simón Abril reside en la novedad de sus ideas y métodos pedagógicos y, por ende, de su libro Apuntamientos de cómo se deben reformar las doctrinas y la manera de enseñarlas (Madrid, 1589) (de Cañigral-Cortés, 1987). 


\subsubsection{Ramírez de Carrión, Manuel (profesor de sordomudos, alqui- mista y precursor de la "Ciencia de la Documentación")}

\section{Hellín (Albacete) 1579 - Valladolid 1654}

Se desconoce su formación inicial, según algunos autores era «maestro en primeras letras». Parece ser que en Hellín pudo enseñar a hablar a un muchacho sordomudo, por lo que se corrió la fama de que «desmutizaba» a los sordomudos, haciéndoles leer, escribir y conversar.

Fue llamado por Pedro Fernández de Córdoba, IV Marqués de Priego, para que se hiciera cargo de la instrucción de su hijo, sordo de nacimiento. Corrió su fama y, tras esta supuesta curación, tuvo reconocidos alumnos, todos ellos «sordos nobles», como Luis de Velasco, el marqués del Fresno, Juan Alonso de Medina y Antonio Docampo. A esta lista habría que añadir, supuestamente, a Emmanuel Filiberto de Saboya y a la hija de los Duques de Medina Sidonia (Gascón y Storch, 2009). Enunció por primera vez en el mundo la teoría de que los sordomudos son solo sordos, y que son mudos porque no oyen, por lo que con técnicas especiales se les puede enseñar a hablar. Su modelo educativo conjugaba el método oral combinado con la dactilología o lenguaje de signos. Es considerado uno de los tres personajes españoles fundamentales para la historia de la educación de los sordos junto a fray Pedro Ponce de León y Juan Pablo Bonet.

A Ramírez de Carrión le atraían las cuestiones naturales, las cosas maravillosas de la ciencia, de la naturaleza. Su obra: Maravillas de Naturaleza, publicada en 1629 tuvo gran repercusión en España (figura 2).

\subsubsection{Izquierdo Monza, Sebastián (matemático, filósofo lógico)}

\section{Alcaraz (Albacete), 1601 - Roma, 1681}

Realizó estudios en la Facultad de Artes de la Universidad de Alcalá, pero también mostró interés por estudiar Matemáticas. Ingresó en la Compañía de Jesús el año 1623. En Madrid residió en el Colegio Imperial, donde existía un altísimo nivel científico. Allí estuvo inmerso en la conjunción de saberes filosóficos, científico-matemáticos, humanísticos y lógicos que influyeron y forjaron su pensamiento. Fue nombrado censor de la Inquisición y, más tarde, asistente del Prepósito General en representación de las provincias de España y de las Indias Occidentales. 
En sus años de docencia publicó su obra fundamental, Pharus Scientiarum (Lyon, 1659) (figura 2), el «faro de las ciencias», que supone una magistral aportación al pensamiento europeo del siglo XVII (Fuertes-Herreros, 1981).

Se trata de una teoría general de la ciencia, un tratado del método del saber científico (dentro de la línea lulista que imperaba en sus días), en el que tienen cabida la lógica tradicional aristotélica y el empirismo baconiano (Adán Oliver, 2015).

\subsubsection{Jareño De la Parra, Mateo (médico)}

${ }^{*}$ Villarrobledo (Albacete) i? - Madrid, 1699

Mateo Jareño de la Parra fue catedrático de Medicina en la Universidad de Salamanca y médico de cámara de Carlos II de España. Estudió teología y llegó a ser nombrado catedrático de la Universidad de Salamanca en 1665. Tan solo un año después, el 6 de junio de 1666, obtuvo la licenciatura en Medicina y el doctorado en dicha disciplina. Hacia 1676 obtuvo la cátedra de Pronósticos. Por esta época escribió su obra que lo llevaría a la fama y le daría prestigio, Methodus medendi ex esaleno .

Mateo Jareño fue un hombre de notable erudición que llegó a atesorar una gran biblioteca científica y de renombre en el campo de la medicina de aquella época. Su enorme reputación en Salamanca llegó a oídos de un rey, como Carlos II de España, famoso por su extremadamente delicada salud. Por tal motivo, el 10 de febrero de 1694 abandonó la docencia para ser nombrado médico de la real cámara (Baquero-Almansa,1884).

\subsection{PARADIGMA POSITIVISTA: campo de las ciencias, la ingeniería y la tecnología}

La corriente de desarrollo tecnológico que corría por Europa y España durante los siglos XVIII, XIX y la primera parte del XX se corresponde con la implantación del paradigma científico positivista. A pesar del crecimiento económico en Albacete por las ferias y el comercio, y de la importancia de la educación entre los ilustrados, la enseñanza en la provincia quedaba relegada a las escuelas de gramática de algunos pue- 
blos que podían pagar a maestros y la labor docente de algunas órdenes religiosas. Los jesuitas, por ejemplo, controlaron la educación en Albacete entre 1709 y 1767, con tan solo cuatro sacerdotes, según el catastro del marqués de la Ensenada (Losa y Cózar, 2002). A petición del municipio de Albacete se crean cátedras de latinidad y, más tarde, en 1817, la de filosofía, pero habría que esperar a mediados del siglo XIX y a sus reformas liberales para encontrar cambios significativos en la educación. En 1841 se crea el primer instituto de Albacete bajo una legislación cambiante que establece distintos niveles para este tipo de centros. Se aprovechan los conventos desamortizados para su ubicación y la matrícula de un alumnado procedente de toda la provincia también obligó a la creación de un alojamiento para estudiantes y, después, de un Colegio Provincial de Internos que muy pronto desapareció por falta de alumnos. (Rodríguez, 2017) $\mathrm{Al}$ año siguiente, se crearía la Escuela Normal (Belmonte, 2010) para la formación de los futuros maestros ubicada también en el desamortizado convento de San Francisco, que, con tan solo dos profesores, muestra su escasa consistencia didáctica. Con las reformas de 1901 de Romanones, los centros de Segunda Enseñanza pasaron a llamarse Institutos Generales y Técnicos en los que se imparten también enseñanzas de magisterio, agricultura, industria, comercio, bellas artes y artes industriales, es decir una especie de universidades provinciales. Algunos de nuestros científicos proceden de estos nuevos centros y la repercusión en las nuevas generaciones fue muy positiva, según recoge el trabajo de Tobarra (2019). Los campos en los que van a desarrollar su trabajo son ya más tecnológicos, como se refleja en el caso de J. J. Graubner, que incorporaría desde Holanda y Alemania conocimientos y tecnología que servirían para el desarrollo de nuestra provincia, concretamente en la comarca de Riópar (Fuster, 1976), así como avances en las ciencias sanitarias (medicina, farmacia y veterinaria). Algunos de estos científicos se recogen en la figura 1. 

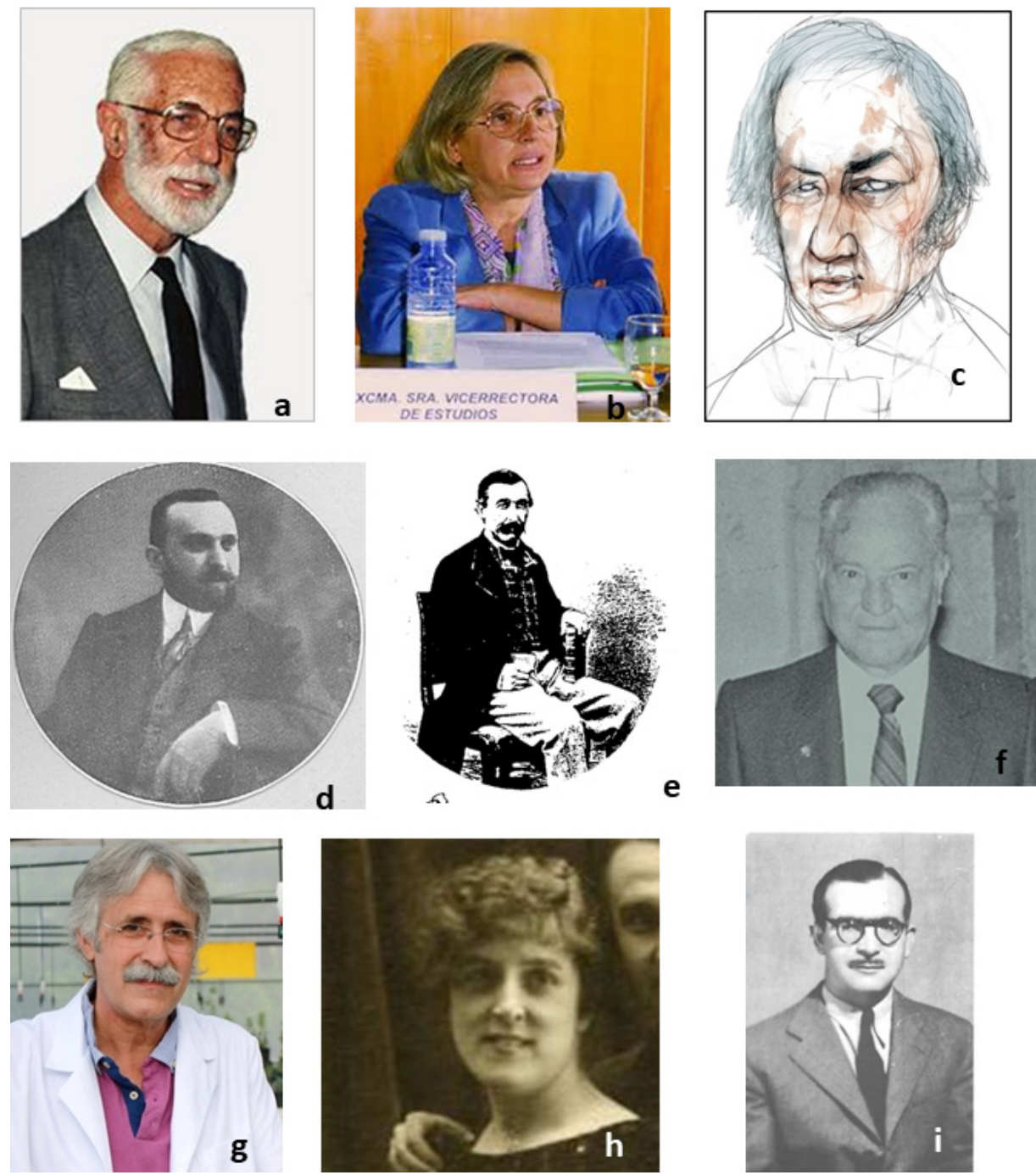

Figura 1. Eminentes científico albacetenses; a.- Leonardo, Villena Pardo (físico). Sedoptica (Sociedad Española de óptica); b.- Mercedes Doval Montoya (geóloga) (fotografía tomada de Galán Huertos, Garíca Romero y Ancochea Soto, 2014); c.- Guillermo Torres Muñoz (farmacéutico) )retrato de Guillermo Torres Muñoz. Fundación Española para la Ciencia y la Tecnología, Eulogia Merle); d.- Ramón Coderque Navarro (veterinario) (fuente: Álbum de eminencias médicas hispano-latinas, tomo 1. Madrid, 1917); e.- Juan Morcillo y Olalla (veterinario) (tomado de Rodríguez de la Torre, 2002); f.- Joaquín Pacual Teresa (químico) (fotografía tomada de: https://cenoceracastillayleon.jcyl.es/web/es/premioscastilla-leon/premios-castilla.leon1984.html); g.- Mario Honrubia (biólogo) (fotografía, Asun Morte); h.- Amparo Irueste Roda (maestra) (Instituto de Estudios Albacetenses); i.- Enrique Tomás Salmerón (Ingeniero Agrónomo) (tomado de Moreno-García, 2011). 


\subsubsection{Graubner, Juan Jorge (técnico metalúrgico)}

Viena (Austria), 1736 - Alcaraz (Albacete), 1801

Formado en técnicas metalúrgicas, en Alemania y Holanda. Viajó en 1771 a Riópar para estudiar las posibilidades de explotación de una mina de calamina (mineral del cinc). De este viaje surgió el proyecto de fábricas de latón y bronce que obtuvo en 1773 la real cédula de parte de Carlos III para su puesta en marcha. Fueron las primeras fábricas de latón de España y las segundas del mundo. Se instalaron en el fondo del valle, para aprovechar la energía hidráulica de las corrientes de agua, alejadas del primitivo núcleo de población. Así, dieron origen a una moderna población que se llamó Fábricas de San Juan de Alcaraz, posteriormente Fábricas de Riópar y, en la actualidad Riópar (González-Calero, 2016).

Graubner amplió el proyecto inicial, basado en la fabricación de barras de latón, con el fin de obtener otras producciones como planchas y alambre de latón y bronce. En consecuencia, se constituyeron en 1787 las Reales Fábricas de San Juan de Alcaraz (figura 2).
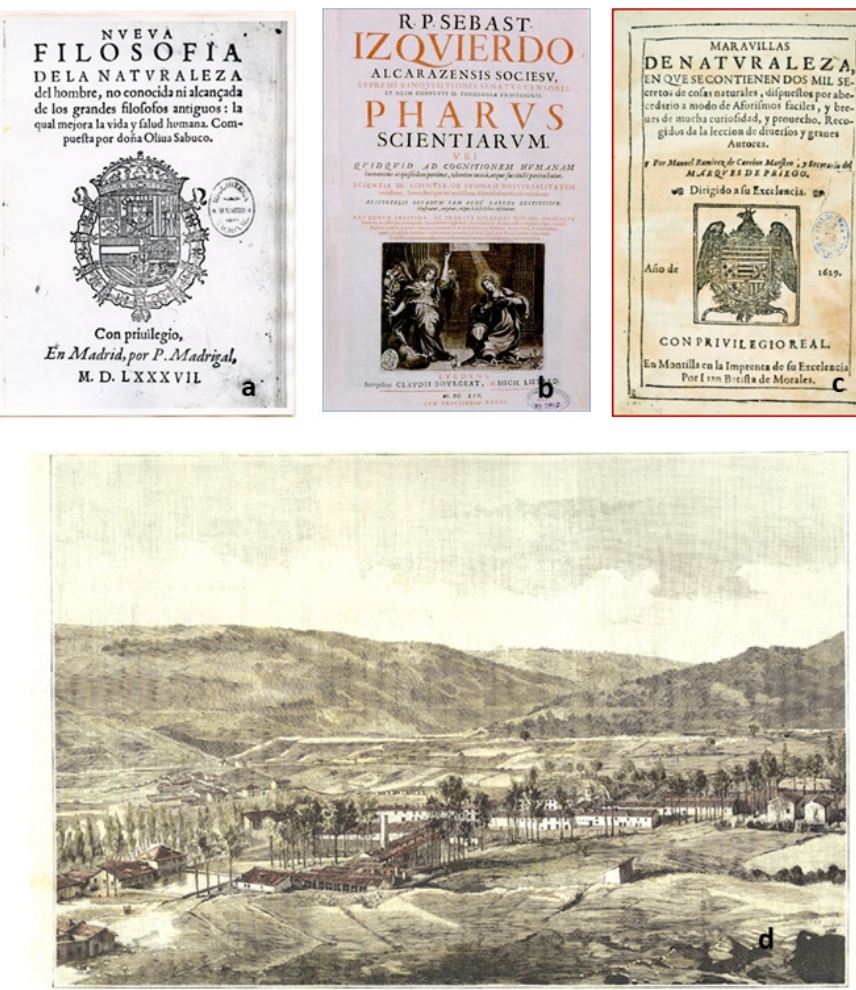

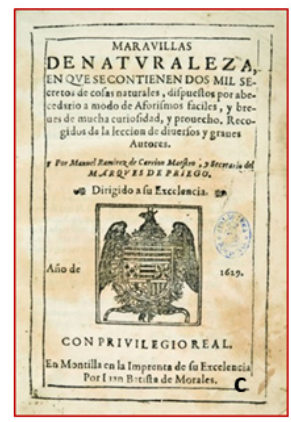

Figura 2. Obras destacadas de algunos científicos albacetenses; a.Nueva Filosofía de la Naturaleza del hombre de Miguel de Sabuco (fuente: Archivo Fotográfico IEA); b.Pharus Scientiarum (1659), Sebastián Izquierdo Moya (imagen: books.google. com); c.- Maravillas de la Naturaleza (1629) de Manuel Ramírez de Carrión (fuente Biblioteca Nacional de España); d.- Fábricas de San Juan de Riópar (Graubner, Juan Jorge). Grabado propiedad del Instituto de Estudios Albacetenses. 


\subsubsection{Martínez Villascusa, Francisco (médico rural)}

Jarafuel (Valencia), 1740 - Tarazona de La Mancha (Albacete), 1793

Obtiene el grado de bachiller en Medicina en 1760 en la Universidad de Orihuela (Alicante), con la revalidación ante el tribunal del Real Protomedicato en Valencia en 1762. Se convierte en médico titular de Villena en 1764 y en médico titular de la ciudad de Alcaraz en 1768. En 1772 se establece en Barrax. Por último, en 1776 ocupa la plaza de médico titular en Tarazona de La Mancha.

Su interés científico le lleva a entrar en varias academias médicas y a mantener correspondencia con médicos insignes españoles y europeos. Fue socio honorario de la Regia Sociedad de Medicina y demás Ciencias de Sevilla.

Su inquietud cultural y filantrópica le empuja a participar en varias Sociedades Económicas de Amigos del País, como la de Soria o la Sociedad Patriótica de Vera. Él mismo promueve la creación de la Junta de Caridad de Tarazona de La Mancha, que construye un hospital para el cuidado de personas pobres (Sánchez García, 2012).

\subsubsection{Morcillo y Olalla, Juan (veterinario, inspección sanitaria, histo- ria de la ciencia)}

Montealegre del Castillo (Albacete), 1828 - Játiva (Valencia), 1908

Graduado en la Escuela de Veterinaria de Madrid en 1851. Desarrolló su vida profesional en el municipio valenciano de Játiva. Creó en 1881 la Asociación Veterinaria de las Riberas del Júcar, que publicaba la revista Alianza Veterinaria. Esta asociación es el origen de del Colegio de Veterinarios de Valencia, primero de España y del que fue nombrado presidente de honor en 1904 (AEHV, 2020).

Miembro y medalla de oro de la Academia Central de Veterinaria Española. Medalla M. H. Boulay de la Sociedad de Medicina Veterinaria Práctica de París.

Su experiencia como veedor de carnes y pescados (lo que hoy sería un inspector de sanidad) y su conocimiento de la patología animal, cons- 
tituyen la base para el desarrollo de una serie de reglas y técnicas pioneras, plasmadas en 1858 en su Guía del veterinario inspector. Esta publicación sienta las bases para un control científico en la producción y comercialización de alimentos y es considerada como la mayor aportación de nuestro país a la ciencia veterinaria moderna (Aganzo-Salido 2009).

\subsubsection{Torres Muñoz, Guillermo (farmacéutico)}

Tarazona de La Mancha (Albacete), 1848 - Madrid, 1931

Es en el siglo XIX cuando encontramos a un personaje relevante de nuestra provincia en el campo de la farmacia. Guillermo Torres Muñoz destacó por su inquietud investigadora, pues fabricó el famoso bicarbonato sódico

Obtuvo el Bachillerato en Artes en el Instituto de Segunda Enseñanza de Cuenca en 1866. Se licenció en la Facultad de Farmacia de la Universidad Central de Madrid en el Colegio de San Fernando, en 1871. Estableció su farmacia en Madrid. Tras elaborar otras fórmulas magistrales, fabricó el bicarbonato sódico que lleva su nombre «Bicarbonato Torres Muñoz», que es una variante del que inventó en Berlín en 1801 el farmacéutico alemán Valentine Rose (1762-1807). Este bicarbonato fue muy popular en la época (se desconoce el año exacto del comienzo de su fabricación). Fue registrado en la Inspección General de Sanidad en 1923, aunque ya aparecen anuncios en las revistas Mundo Gráfico (1915) y La Esfera (1916). El Bicarbonato Torres Muñoz era comercializado y anunciado como: «El mejor remedio para el estómago, bicarbonato de sosa químicamente puro, antirreumático, antigotoso y antidiabético, en polvo y en comprimidos». Se anunció también como hemostático y cicatrizante. Posteriormente adaptó la fórmula y prepararía también jabón y crema bicarbonatada (Díez-Barra y González-Calero, 2020).

\subsubsection{Collado Piña, Andrés (médico)}

Albacete, $1849-\dot{i}$ ?

Cursó estudios de bachiller en el Instituto de Segunda Enseñanza (hoy Bachiller Sabuco) durante los años 1860-1866. Destacó en el campo 
de la medicina por sus conocimientos técnicos y por su cercanía a la gente, pues dedicó también parte de su vida a la política. Durante su dilatada carrera en medicina ocupó el cargo de médico de la beneficencia, al cual renunció en mayo de 1878, y ocupó el puesto de director del Hospital de San Julián de 1881 a 1882 y desde 1884 a 1886. En el año 1883 dirigió los baños medicinales de Mula (Murcia).

En 1885 escribe un tratado de puericultura con el título: «Higiene de la infancia», dirigido a las madres para que conociesen de buena mano cómo cuidar y prevenir la salud de sus hijos. Fue un personaje especialmente preocupado por los problemas sanitarios de Albacete y su provincia, debate que mantuvo vivo durante años, a través de la publicación de numerosos artículos relacionados con el tema en la prensa local (Gómez García, 1980).

\subsubsection{Pereda González, Tadeo (inventor de la laringe artificial)}

Almansa (Albacete), 1864 - Almansa (Albacete), 1955

Curiosamente Tadeo Pereda, no era científico, su profesión era comisionista de vinos y guarnicionero (Hernández-Cutillas, 2014). Como consecuencia de un epitelioma (tumor cancerígeno) le extirparon la laringe y perdió el don de la palabra. Tras su fracaso al probar el aparato fonador del médico berlinés Dr. Gluk y posteriormente el modelo francés Delair, Tadeo Pereda comenzó a estudiar la posibilidad de fabricar su propio aparato fonador que le permitiese la emisión de los sonidos. En 1912 inscribió su invento en el Registro de Patentes y Marcas. Se presentó el aparato en el Congreso de Otorrinolaringología celebrado en Bilbao en 1912 y en 1921 en el Congreso Internacional de Otorrinolaringología celebrado en París. Toda la comunidad científica y la prensa de la época se hicieron eco del invento que tuvo una aceptación unánime y fue reconocido por los especialistas y cirujanos de toda Europa. HernándezCutillas (2006) escribe acerca de este personaje: "su modestia de hombre de pueblo, una familia numerosa a la que sustentar y el no ser un hombre de ciencias, le debieron coartar y desistir de las invitaciones hechas por universidades europeas y americanas". 


\subsubsection{Carpena Pellicer, Fructuoso (antropólogo criminal)}

Jumilla (Murcia), $1870-{ }^{\star}$ ??, 1936 o posterior

Era licenciado en derecho y fue notario en Hellín. Se interesa por la redención de los delincuentes encarcelados, hasta tal punto que deja su puesto de notario para dedicarse al estudio de este tema. De los resultados de sus investigaciones surgió en 1909 Antropología criminal, obra con más éxito fuera que dentro de España, que le abre las puertas de la publicación en revistas especializadas extranjeras y la posibilidad de ganarse la vida con sus colaboraciones. En 1910 era miembro de la academia de Jurisprudencia y Legislación.

Alrededor de Carpena se crea un grupo de interesados en las ciencias penales que da lugar al Instituto Criminológico Español (Moreno García, 2011 y Tomás Ibáñez, 1993).

\subsection{CRISIS DEL POSITIVISMO Y POSTMODERNIDAD: nuevos campos científicos}

En la coyuntura del período de entreguerras y especialmente tras la II Guerra Mundial, se va a producir una gran revolución científica que daría paso a la actualidad. En España coincide con el regeneracionismo y el desarrollo cultural durante la II República. Sin embargo, la Guerra Civil y la emigración de muchos intelectuales retrasan la incorporación de España a las nuevas corrientes científicas. Tenemos que esperar a que llegue el siglo XX para encontrar personajes de nuestra provincia (figura 1) que destacaran en los nuevos campos de la Física (astrofísica y metrología), química, geología, biología, las ciencias de la salud, economía, pedagogía, antropología y el resto de disciplinas cada vez más especializadas y tecnologizadas. En Albacete, al carecer de universidad, la mayor parte de los científicos se siguen formando en Madrid y en las ciudades del Levante, salvo los que tienen que emigrar por razones políticas principalmente al extranjero.

\subsubsection{Coderque Navarro, Ramón (médico, veterinario)}

Munera (Albacete), 1877 - León, 1961 
Cursó la licenciatura y el doctorado en Medicina en la Facultad de la Universidad Central de Madrid y estudió Veterinaria en la Escuela de Veterinaria de León. Fue becado por el gobierno para ampliar estudios de microbiología en el Instituto Pasteur de París y para estudios y experimentación sobre el cáncer en la Estación Científica de la Real Clínica Universitaria de Berlín. Ejerció la medicina en Madrid y posteriormente, ejerció en León como cirujano médico y catedrático de Patología Quirúrgica en la Escuela Veterinaria. Fue el primero que descubrió el Trypanosoma nabiasi del conejo en España. Destacó también por la preparación de distintas vacunas (anticarbuncosa, de la maleína, y de la tuberculina). Además, fue presidente del Colegio Oficial de Médicos de León y vicepresidente de la Asociación Nacional Veterinaria (Cordero del Campillo, 1982).

\subsubsection{Irueste Roda, Amparo (Magisterio, metodología en Ciencias)}

\section{Granada, 1886 - Madrid, 1975}

Estudió en la Escuela de Estudios Superiores del Magisterio. Fue nombrada el 2 de julio de 1913 profesora auxiliar de la Sección de Ciencias de la Escuela Normal de Maestros de Ciudad Real. En 1915 ejercerá como profesora de Ciencias Físico-Químicas y de Historia Natural en la Escuela Normal de Maestras de Albacete, donde desempeñaría el cargo de directora hasta 1951.

Viajó a Francia y Bélgica en el verano de 1913 para visitar escuelas, estudiar su organización y conocer las instituciones pedagógicas de estos países. Trabajó los métodos de investigación para el estudio de los grados de inteligencia. Tras la elaboración de un estudio de más de 3000 niños/ as españoles, llegó a la conclusión de que estos iban retrasados en algo más de dos años respectos a los niños franceses en cultura general y de tres en cuanto a las materias de ciencias naturales, de física y de matemáticas. En su estudio deduce que «no es el tipo de alimentación o la falta de higiene lo más importante en el desarrollo de la inteligencia, sino que son los métodos de enseñanza los que producen estancamiento, cuando no represión, del desarrollo intelectual de los niños españoles» (Benito Santos, 2012). 


\subsubsection{González Duarte, Plácido (médico, cirujano)}

Carcelén (Albacete), 1897- Madrid, 1986

Estudió la carrera en la Facultad de San Carlos de Madrid, donde obtuvo su licenciatura y doctorado con la tesis "Contribución al estudio de las fracturas de fémur». Tras estudiar en París, Fráncfort y Estrasburgo desempeñó la medicina en distintas instituciones, tanto públicas como privadas: la Casa Real, el Hospital de la Princesa, el sanatorio de Valdelatas, el Complejo hospitalario Ruber, etc. Fue profesor agregado hasta el comienzo de la Guerra Civil, en la que operó a los heridos en todos los quirófanos de campaña madrileños que se improvisaron y fue, además, además uno de los creadores de la famosa «Cura española» o «Cura Duarte.

Sobresalió sobre todo en las ramas de especialización de cirugía del esófago, cáncer de pulmón y tórax en general, campos en los que fue una referencia mundial, y a los cuales incorporó diversas novedades técnicas y en los que se distinguió por sus innovaciones personales. Fue miembro del Comité Científico de la Sociedad Internacional de Cirugía, presidente del Congreso Nacional de la Asociación Española de Cirujanos, miembro honorario de las Sociedades de Cirugía de México, París y Londres, etc. (Almendros-Toledo, 1997).

\subsubsection{Almendros Ibáñez, Herminio (pedagogo)}

Almansa, 1898 - La Habana (Cuba), 1974

Formado como maestro en la Escuela Normal de Alicante, posteriormente fue becado en la Escuela de Estudios Superiores del Magisterio en Madrid, en la especialidad de Ciencias. Fue profesor y director del Centro de Formación Agrícola e Industrial de Villablino (León), inspector de Enseñanza Primaria, docente en la Universidad de Barcelona... Se definió pedagógicamente como un hombre de ciencia, influido por las nuevas corrientes educativas y por el pedagogo francés Célestin Freinet. Tras la Guerra Civil, tuvo que exiliarse a La Habana (Cuba), donde desempeñó distintos e importantísimos puestos, relacionados con la educación y la pedagogía, la cultura, la literatura infantil y juvenil, la alfabetización y el 
mundo editorial. Su obra es de un extraordinario valor actual y constituye una aportación indispensable para el perfeccionamiento de la tarea educativa (Blat Gimeno, 1998).

\subsubsection{José Pérez Mel (médico)}

Valadouro (Lugo), $1901-{ }^{\star} i$ ?, 1974

José Pérez Mel, médico bacteriólogo que ocupó en la provincia de Albacete el cargo de inspector provincial de Sanidad en los años treinta de la anterior centuria. Pérez Mel llevó a cabo una intensa labor de reformas sanitarias y de higiene, pioneras en la España rural, y fue el promotor del plan de estudios de enfermería que los gobiernos republicanos intentaron implantar. Desarrolló un proyecto con la Fundación Rockefeller con la idea de crear un centro sanitario provincial y una red de centros de atención primaria y secundaria situados en lugares estratégicos.

Cabe destacar la gran labor de J. Pérez Mel como profesor y autor del proyecto sobre la creación de un plan de estudios para las nuevas escuelas de enfermería que los gobiernos de la Segunda República intentaron implantar, pero que la Guerra Civil impidió. Nuestro inspector-profesor propuso un plan de acceso a la carrera de Enfermería con la titulación de Bachillerato o de Maestra Nacional y de tres años de duración (Lucas Picazo, 2020).

\subsubsection{Pascual Teresa, Joaquín (químico, tecnología química)}

Caudete (Albacete), 1915 - Salamanca, 1998

Estudio químicas en Valencia (1931-1936). Fue profesor de instituto. Se doctoró en 1943 en la Universidad Central de Madrid, y desde 1941 perteneció al Consejo Superior de Investigaciones Científicas (CSIC). En 1949 obtuvo la cátedra de Química Orgánica y Bioquímica de la Facultad de Ciencias de la Universidad de Salamanca.

Sus primeros trabajos de investigación se centraron en las reacciones de sales de sulfonio y otros derivados de azufre, y en la síntesis de halógeno-azúcares y de hidroxiácidos grasos. Tras aquellos trabajos pioneros, fue simultaneando las investigaciones sobre reactividad y transfor- 
maciones químicas de terpenos y esteroides con los estudios fitoquímicos de plantas. Nombró un alcohol natural aislado de té de roca (Chiliadenus glutinosus (L.) Fourr.) «kudtdiol», en honor a su pueblo de nacimiento (KU-D-T=Caudete).

Estuvo en la Comisión Nacional de Estudios de las Facultades de Ciencias Químicas y, por propuesta suya, en 1953 se implantó la realización de la licenciatura experimental (tesina) para la consecución del grado de licenciado, así como la posibilidad de que todas las universidades españolas pudieran conceder el grado de Doctor (Díez Barra y GonzálezCalero, 2020).

\subsubsection{Tomás Salmerón, Enrique (ingeniero agrónomo, aguas subterrá- neas)}

Hellín (Albacete), 1916 - Madrid, 1970

En 1945 fue destinado a Ciudad Real como ingeniero agregado. Durante su permanencia se encargará de coordinar y ejecutar las primeras tomas de riego del primero y segundo sector de la llamada «zona de La Mancha». En 1954 es trasladado a Madrid y entra a formar parte del Servicio de Aguas Subterráneas, donde dirigirá las obras de captación de aguas subterráneas en El Pasico y El Salobral (Albacete). Durante estos años de trabajo en la zona de Los Llanos de Albacete, Enrique Tomás profundiza sus investigaciones sobre el ciclo de las aguas subterráneas, ampliando de esta manera sus conocimientos geológicos.

Su trabajo Aguas subterráneas: Acuíferos a Presión, publicado por el Ministerio de Agricultura, resultó innovador en el campo de la hidrogeología y aportó nuevos conocimientos sobre el comportamiento de las aguas subterráneas, que hasta entonces eran totalmente desconocidos (Moreno García, 2011).

\subsubsection{Precioso Ugarte, Artemio (economista, activista ambiental)}

Hellín (Albacete), 1917 - Madrid, 2007

Comenzó estudios de derecho en Madrid, interrumpidos por el comienzo de la Guerra Civil. Se exilió a la URSS, de donde parte en 1946, 
Desde la URSS, se establece en Yugoslavia primero y en Checoslovaquia después. En Praga retoma estudios universitarios de economía, de los que llegó a doctorarse y, además, obtuvo la cátedra de Macroeconomía. Es en este campo donde destacará por el estudio de las relaciones entre economía y ecología.

En 1960 regresa a España. Nunca dejó su activismo político. Se integró en el incipiente movimiento ecologista. Continuó con la divulgación de sus ideas sobre la relación entre ciclos naturales y movimientos políticos y sociales, incorporando un nuevo término, la socioecología. En ese marco crea el Centro de Estudios Socioecológicos, que participa en la organización de las Jornadas de Ecología y Política, celebradas en diferentes ciudades españolas. Fue uno de los fundadores de Greenpeace España en 1984, siendo su secretario general durante varios años y presidente honorario desde 2004. En 2006 recibe el Premio Nacional Extraordinario de Medio Ambiente (Barcia, 2007 y Bigues et al., 2018).

\subsubsection{Villena Pardo, Leonardo (físico, metrólogo)}

Casas de Ves (Albacete), 1917 - Madrid, 2015

Licenciado en la Universidad Complutense de Madrid por Ciencias Físicas. Investigador del Instituto de Óptica del CSIC, impulsor de la metrología y la calidad en España y miembro durante 30 años del Comité Consultivo de Unidades del Comité Internacional de Pesas y Medidas. Estuvo involucrado en los trascendentales cambios que se estaban produciendo para el Sistema Internacional de Unidades y en la actualización continua de la publicación «Le Systeme International d'Unités». Responsable de la creación de la Asociación Española para la Calidad, con un comité específico sobre metrología. Es considerado uno de los padres de la metrología moderna en España y uno de los principales impulsores e investigadores de la ciencia óptica del país. Además, es fundador de la Asociación Nacional de Físicos de España y socio de honor de la Sociedad Española de Óptica.

Su principal monografía es: «Fotoelasticidad». publicada por el Instituto Técnico de la Construcción y Edificación del Consejo Superior de Investigaciones Científicas, 1942 (Gómez-Peñalver, 2007). 


\subsubsection{Rodríguez de la Torre, Fernando (investigador histórico, geógrafo)}

Albacete, 1932 - Madrid, 2013

Obtuvo la licenciatura en Geografía e Historia (Murcia) y el doctorado en Geografía Física (Barcelona). Hacia 1977 empezó a estudiar la geografía e historia de los seísmos, convirtiéndose en una autoridad y reconocido especialista en sismicidad histórica, con los materiales reunidos elaboró su tesis doctoral: «Sismicidad y sismología en la Península Ibérica durante el siglo XIX».

Como experto bibliógrafo recopiló ingente documentación para sus distintas líneas de investigación: sismología, astronomía, geografía, geología, desastres naturales, folklore y etnología, ingeniería y tecnología, la Guerra Civil y las Brigadas Internacionales, bibliografía, musicología, etc.

Colaboró con el Instituto Geográfico Nacional (Madrid) y el Consiglio della Ricerca Scientifica Italiana (Roma), que suscribieron con él contratos de investigación para que reevaluara sus catálogos históricos de terremotos, con la Biblioteca Nacional, Archivo Histórico Nacional y varios Centros de Estudios Locales.

Fue Colegiado de Honor del Colegio de Doctores y Licenciados de Madrid, miembro del Instituto de Estudios Albacetenses, de la Comisión de Historia de la Geología en España y de la European Seismological Commission (Díez Barra y González-Calero, 2020).

\subsubsection{Doval Montoya, Mercedes (geóloga, decana, vicerrectora)}

Albacete, 1947 - Madrid, 2011

Licenciada en Ciencias Geológicas en 1970 en la Facultad de Ciencias de la Universidad Complutense de Madrid y doctora en Geología en 1975. Docente desde 1970, obtiene la Cátedra de Cristalografía y Mineralogía en 1988. Socia fundadora de la Sociedad Española de Mineralogía. Su trabajo investigador se centra en la mineralogía de la arcilla.

Creó el Centro de Espectrometría, que dio lugar al Centro de Asistencia a la Investigación de Técnicas Geológicas de la Universidad Complutense, del que fue directora hasta su muerte. 
Además de un gran número de artículos relacionados con su campo de investigación, publicó algunas aportaciones sobre su experiencia en la gestión universitaria (Díez Barra y González-Calero, 2020).

\subsubsection{Sáez Milán, Diego Pascual (astrofísico)}

Almansa (Albacete), 1952 - Valencia, 2018

Licenciado y doctorado en Ciencias Físicas por la Universidad de Valencia, en la especialidad de Física Teórica. Su tesis doctoral fue: «Contribución a una nueva teoría relativista de gravitación».

Estudió Cosmología e investigó el fondo cósmico de microondas estándar (modelo del Bing-Bang) y en la Universidad de Berkeley colaboró con el premio nobel de física G.F. Smoot en la investigación sobre El Gran Atractor, los grandes Vacíos y el Proyecto Cobras. Como catedrático de la Universidad de Valencia, en el Departamento de Astronomía y Astrofísica, dirigió un equipo de investigación realizando simulaciones sobre el llamado posicionamiento relativista y dirigió numerosas tesis doctorales.

Fue miembro numerario de la Sociedad Española de Astronomía (SEA), de la Sociedad Española de Relatividad y Gravitación (SEGRE) y de la American Association for the Advancement of Science (HernándezCutillas 2014).

\subsubsection{Honrubia, Mario (biología. micología. investigación en micorrizas)}

Almansa (Albacete), 1956 - Murcia, 2015

Fue catedrático de Biología Vegetal (Botánica) en la Universidad de Murcia. Cabe destacar que presumía de su origen almanseño. Estudió Biología en la Universidad de Valencia y se doctoró en la Universidad de Murcia en el año 1982.

Como biólogo, Mario Honrubia logró la convivencia pacífica de las dos almas que caracterizan a la profesión. Por un lado, ejerció como biólogo de campo, y por otro, trabajó como biólogo de laboratorio, sin apartar la vista de la lupa binocular y el microscopio. 
Mario fue pionero en el estudio de las ectomicorrizas en nuestro país, con lo que creó una escuela reconocida a nivel nacional e internacional. El profesor Honrubia desarrolló diferentes líneas sobre el estudio de las micorrizas aplicadas al cultivo de hongos hipogeos como algunas especies de los géneros Terfezia y Tuber, entre otros, dirigiendo varias tesis doctorales sobre ectomicorrizas y micorrizas arbusculares. A lo largo de su carrera científica participó en más de 75 proyectos de investigación (regionales, nacionales, internacionales, acciones integradas bilaterales, contratos de I+D) y en más de 200 publicaciones (Moreno y Manjón, 2016).

\section{CONCLUSIONES}

Aproximarnos al conocimiento de la historia de la ciencia de nuestra provincia, un territorio de reciente creación, desde el punto de vista histórico, no sería posible si no fuera por los personajes que han habitado en los diferentes territorios y localidades que hoy la conforman, y que han desempeñado un importante papel en los diferentes campos de la ciencia, cada uno de ellos en su época respectiva. Son veintisiete personajes, solo tres de ellos mujeres (si tenemos en cuenta también a Oliva Sabuco de Nantes), los que nos han servido para adquirir una aproximación a la historia de la ciencia en nuestra provincia.

Una reflexión que podemos extraer de la relación de científicos es que tan solo hallamos a tres mujeres, lo cual es indicativo de las dificultades para acceder a determinadas áreas de conocimiento por parte de las mujeres.

Tres son los periodos en los que podemos configurar la historia de la ciencia en la provincia de Albacete. Un primer periodo que abarca los siglos XVI y XVII, pues es a principios del siglo XVI cuando encontramos referencias al primer personaje, originario de la ciudad de Alcaraz. Asimismo, es en este período, coincidente con el Renacimiento, en el que podemos destacar como personaje más relevante al Bachiller Sabuco. De los siete personajes de este periodo, seis son originarios de Alcaraz, lo cual nos demuestra el importante centro económico, cultural y de conocimiento, que por aquella época representaba esta ciudad serrana. 
Un segundo período que abarca los siglos XVIII y XIX, en el que la corriente de desarrollo tecnológico que corría por Europa también se ve reflejada en estas tierras, y en el que destaca Graubner como uno de los mejores representantes de este periodo, como lo demuestra la creación de las fábricas de latón y bronce por estas tierras en lo que se conoce como Fábricas de Riópar. Merece la pena subrayar la figura de Tadeo Pereda, autodidacta e inventor, que sin estudios académicos previos, fue sobradamente reconocida en el campo de la ciencia de esta época. En este periodo fue clave la creación del Instituto de Enseñanza Secundaria en Albacete y la Escuela Normal, lo que facilitó el acceso a estudios a un mayor número personas.

$\mathrm{Y}$ un tercer período, situado en el siglo XX, coincidiendo con la gran revolución científica que tuvo lugar después de la II Guerra Mundial, en el que encontramos a la mayoría de científicos y científicas que estudian nuevas disciplinas de reciente incorporación al mundo de la ciencia como son la física, química, geología, biología, pedagogía o incluso la economía trabajada desde una perspectiva medioambiental. Aquí es difícil destacar tan solo a uno, pues todos ellos son eminentes científicos, cada uno en su respectivo campo, que han desarrollado su labor en el mundo universitario.

Esta provincia estuvo distanciada de los centros de conocimiento y de producción cultural históricamente, por lo que entendemos que han sido dos fechas las que han supuesto un avance y un punto de inflexión en el desarrollo de la ciencia de nuestra provincia: 1841, fecha de creación del Instituto de Enseñanza Secundaria de Albacete, lo que hoy conocemos como Instituto Bachiller Sabuco y la Escuela Normal de Albacete, y, 1985, fecha de la fundación de la Universidad de Castilla-La Mancha y su campus de Albacete.

Por último, es preciso apuntar que, a pesar de la investigación llevada a cabo, probablemente haya más personajes que no están aquí recogidos, lo que puede servir de punto de partida para futuros trabajos de investigación en esta línea, que nos vayan dando algo más de luz acerca de la historia de la ciencia en nuestra provincia. 


\section{AGRADECIMIENTOS}

A Aurelio Pretel y Carlos Ayllón por todos sus comentarios que nos dieron luz para aproximarnos al contexto histórico de nuestros protagonistas. A Ana Lucas Espín y José Fajardo por la revisión del texto.

\section{BIBLIOGRAFÍA}

Adán Oliver, M. (2015). Sebastián Izquierdo, matemático barroco. En Rodríguez, F. y Castellanos, V. (coord.): El Quijote dilatado, pp. 11-36. Ediciones Santa María de Alarcos. Ciudad Real. 327 pp.

AEHV (2020). Asociación Española de Historia de la Veterinaria. Disponible en: https://www.historiaveterinaria.org/update/libro colegio veterinarios almeria.pdf (último acceso 22-12-2020).

Aganzo-Salido, F. (2009). Algo más sobre la vida y la obra de Juan Morcillo y Olalla (1828-1908) en el centenario de su muerte. Anales de la Real Academia de Ciencias Veterinarias, 17: 55-85.

Almendros-Toledo, J.M. (1997). El Doctor Don Plácido González Duarte (1897-1986), perfil vital de un gran cirujano albacetense. Al-Basit, 41: 255-277.

Ayllón, C. (2002). La Orden de los Predicadores en el sureste de Castilla. Instituto de Estudios Albacetenses. Albacete. 183 pp.

Ayllón, C. (2015). Iglesia Rural y sociedad en la Edad Media (Alcaraz y Señorío de Villena). Instituto de Estudios Albacetenses y Silex Universidad. $400 \mathrm{pp}$.

Ayllón, C. (2019). El Santo Oficio en tierras albacetenses, Editorial Almud. $224 \mathrm{pp}$.

Azaola-Piazza, B. (2007). La Escuela de Traductores de Toledo: Pasado, presente y futuro. Idea La Mancha, Revista de Educación de Castilla La Mancha, 5: 122-129.

Baquero-Almansa, A. (1884). Hijos ilustres de la provincia de Albacete. Imp. de A. Pérez Dubrull, Madrid. 274 pp.

Barcia, J.V. (2007). Artemio Precioso Ugarte. Disponible en: ttps://www. ecologistasenaccion.org/90425/prueba-noticia-programada/ (último acceso 18-05-2020) 
Belmonte, F. (2010). La Escuela Normal de maestros de Albacete (18421900). Ediciones de la Universidad de Castilla-La Mancha. 374 pp. Benito Santos, M.S. (2012). Amparo Irueste Roda. En Sánchez-Sánchez, I. y González-Calero, A.: Educación, ciencia y cultura en España: auge y colapso (1907-1940): pensionados de la JAE, pp. 271-272. Almud Ediciones-Centro de Estudios de Castilla La Mancha. 557 pp.

Blat Gimeno, A. (1998). Herminio Almendros Ibáñez: Vida, época y obra. Revista Añil, 16: 63-66.

Bigues, J., Costa Morata, P., Ugarte M., Carrera M. y Linares F. (ed.) (2018). Artemio Precioso Ugarte (1917-2007). La lealtad y el entusiasmo. Instituto de Estudios Albacetenses. Albacete. 142 pp.

Burgueño, J. (1995). La reforma de la división provincial castellano-leonesa en la revolución liberal. Estudios Geográficos, 56 (220): 355-376.

Burgueño, J. (2014) De los reinos de España a la España de las provincias, una dialéctica histórica aún sin ganadores. En de Sousa, F. (coord.): Os Governos Civis de Portugal e a Estruturação Político-Administrativa do Estado no Ocidente. p. 196-220. Centro de Estudos da População, Economia e Sociedade. Porto. 306 pp.

Carpio, J. (1977). La provincia de Albacete entre las antiguas organizaciones territoriales y los futuros proyectos regionales. Albasit, 4: 42-54. Cordero del Campillo, M. (1982). Personajes de la Escuela de Veterinaria de León. Los Coderque: Don Juan Antonio Coderque Téllez, Don Ramón y Don Juan Coderque Navarro. Boletín de Información Científica de los Laboratorios Syva, 282: 149-151.

De Cañigral-Cortés, L. (1987). P. Simón Abril y M. Sabuco: coincidencias programáticas en pedagogía y reforma de la enseñanza. Al-Basit, 22: 43-53.

Díez-Barra, E. y González-Calero, A. (coord..). (2020). Ciencia y tecnología en Castilla-La Mancha. Diccionario biográfico (nombres y hechos). Almud, ediciones de Castilla La Mancha. Ciudad Real. 582 pp.

Fuertes-Herreros, J.L. (1981). La lógica como fundamentación del arte general del saber en Sebastián Izquierdo. Universidad de Salamanca e Instituto de Estudios Albacetenses. Salamanca. 334 pp.

Fuster, F. (1976). Las Fábricas de Riópar, pioneras de la industria metalúrgica española. Al-Basit, 2: 51-68. 
Fuster, F. (1981). Para una historia del regionalismo manchego: la bandera y el himno de La Mancha. Al-Basit, 9: 5-28.

García, J. L. (1976) Antropología del Territorio. Taller de Ediciones Josefina Betancour, Madrid. 350 pp.

García-Serrano, R. y González-Calero García, A. (coord.) (1999). Enciclopedia de Castilla-La Mancha. Biografías. Volumen 10. Ediciones Corporativas (Edicsa 92). Madrid.

Gargantilla, P. (2019). ¿Qué es el método Científico? Estos son sus cinco pasos. ABC.es. Disponible en: https://www.abc.es/ciencia/abcimetodo-cientifico-estos-cinco-pasos-201902170129 noticia.html (último acceso 2-09-de 2020).

Gascón, A. y Storch, J.G. (2009). Manuel Ramírez de Carrión, maestro de sordos en el Siglo XVII: Nuevos apuntes biográficos. Disponible en: https://cultura-sorda.org/manuel-ramirez-de-carrion/ (último acceso, 02-05-2020).

Gómez García, F. (2016). Albacete, 1890. Crónica de Albacete y provincia $y$ otros aconteceres de la época. Tomo I. Uno Editorial. Albacete. 600 pp.

Gómez-Peñalver, J. (2007). Leonardo Villena Pardo. En Casas de Ves y su historia, 277-279. Casas de Ves (Albacete)

González-Calero (Coordinador) (2016). Castilla y La Mancha en el siglo XVIII. Aproximación y miscelánea. Almud Ediciones de Castilla La Mancha, $635 \mathrm{pp}$.

Guillermo Torres Muñoz. Disponible en: https://es.wikipedia.org/wiki/ Guillermo Torres Mu\%C3\%B1oz

(último acceso: 18-09-2020).

Henares, D. (1976): El bachiller Sabuco en la filosofía médica del renacimiento español, Albacete. Delegación Provincial de Información y Turismo. $122 \mathrm{pp}$.

Henares, D. (1984). El pensamiento a través de la historia de Albacete. Boletín de Información "Cultural Albacete", 10: 3-14.

Hernández-Cutillas, A. (2006). Tadeo Pereda González, inventor de la Laringe Artificial. Revista de Estudios Yeclanos, 16: 145-177.

Hernández Cutillas, A. (2014). Almanseños. Almansa. Ayuntamiento de Almansa. 
Kuhn, T. (1992). La estructura de las revoluciones científicas (1ª reimp.). Fondo de Cultura Económica. Santafé de Bogotá. 351 pp.

López-Piñero, J. M. (1979). Ciencia y técnica en la sociedad española de los siglos XVI y XVII. Ed. Labor. Barcelona. 511 pp.

López Piñero, J. M., Glick, T. F., Navarro Brotons, V., y Portela Marco, E (1983). Diccionario histórico de la Ciencia moderna en España. Ediciones. Península. 560 pp.

Losa, P. y Cózar, R. (2002). La secularización de la enseñanza en Albacete a partir de la expulsión de los jesuitas. Revista de Historia Moderna (Anales de la Universidad de Alicante), 20: 5-37.

Madoz, P. (1987). Diccionario Geográfico-Estadístico-Histórico de España $y$ sus posesiones de ultramar. Madrid 1845-1850. Vol. I. Edición facsímil de la parte correspondiente a Castilla-La Mancha de Sánchez Zurro, D. Edit. Ámbito Ediciones, S. A. y Servicio de Publicaciones de Castilla-La Mancha. Salamanca. 481 pp.

Mateos y Sotos, R. (1986). Bonifacio Sotos Ochando (ensayo biográfico). Al-Basit, 19: 135-148.

Mellizo, C. (1996). Miguel Sabuco, Filósofo de Alcaraz. En La Memoria Fiel: Grandes personajes en la historia de Albacete, 77-86. Cultural Albacete Albacete.

Mencía -Valdenebro, I. (2005) Morcillo y Olalla, Juan. Veterinario. Pionero de la inspección veterinaria en España. Disponible en: https:// www.historiaveterinaria.org/update/biografia-morcillo-olalla-1456491338.pdf (último acceso 5-10-2020).

Moreno-García, A. (2011). Hellineros Ilustres. Instituto de Estudios Albacetenses. Albacete. 368 pp.

Moreno-García, A. (2013). In Memoriam. Don Fernando Rodríguez de la Torre. Al-Basit, 58: 381-382.

Moreno, G y Manjón, J. L. (2016). Mario Honrubia. Una vida docente e investigadora. Eubacteria, 36: 10-11.

Moret, J. V. J., Serra, A. N., Cabañes, H. S., Córcoles, M. M., Ballester, L. D., Díaz, J. N., y García, S. V. (2018). De lo tangible a lo intangible: renderizando Patrimonio Histórico Veterinario. En Actas del XXIV Congreso nacional y XV Iberoamericano de historia de la veterinaria: Almería del 26 al 28 de octubre de 2018: 105-112 pp. Colegio Oficial de Veterinarios de Almería. 
Lucas Picazo, M. (2020). José Pérez Mel y los médicos olvidados. Disponible en https://diariosanitario.com/jose-perez-mel-medico/ (último acceso 26-10-2020).

Prados-García, C. (2018). Los estudios superiores en las madrazas de Murcia y Granada. Un estado de la cuestión. Murgetana, 139: 9-21. Pretel, A. (1986). Conquista y primeros intentos de repoblación del territorio albacetense. Instituto de Estudios Albacetenses. Albacete. 303 pp.

Pretel, A. (1999). Alcaraz en el siglo de Andrés de Vandelvira, el Bachiller Sabuco y el preceptor Abril. Instituto de Estudios Albacetenses. Albacete. 459 pp.

Real Academia de la Historia (2018a). Fructuoso Carpena Pellicer, Fructuoso. En Real Academia de la Historia, Diccionario biográfico. Disponible en http://dbe.rah.es/biografias/48113/fructuoso-carpenapellicer (último acceso 5-10-2020).

Real Academia de la Historia (2018b). Graubner, Juan Jorge. En Real Academia de la Historia, Diccionario biográfico. Real Academia de la Historia. http://dbe.rah.es/biografias/36890/juan-jorge-graubner (último acceso 2-10-2020).

Revenga de, F.J.D. (2008). Tomás Navarro Tomás, maestro de la filología española. Al-Basit, 51: 91-112.

Rivera, D. (1984). Historia de la exploración botánica de la provincia de Albacete. En Instituto de estudios Albacetenses (edit): Congreso de Historia de Albacete, (4) 707-744. Albacete 745 pp.

Rodríguez, A .(2017). El Instituto de Segunda Enseñanza de Albacete entre1840-1900, en López, C. y Sanz, R.: Los Instrumentos del Saber. El Instituto Histórico Bachiller Sabuco de Albacete, 53-63 Asociación de Amigos del Museo de Albacete. Albacete. 449 pp.

Rodríguez de la Torre, F. (1987a). El autor y la autoría en la obra de Sabuco. Al Basit, 22: 191-213.

Rodríguez de la Torre, F. (1987b). A la búsqueda de la historia de la ciencia y de la técnica albacetenses. Boletín de Información "Cultural Albacete", 10: 95-105.

Rodríguez de la Torre, F. (2002). El albacetense Juan Morcillo y Olalla, cumbre de la veterinaria española. En Panadero, C. y Requena M. 
(Coord.): II Congreso de Historia de Albacete IV edad contemporánea, 217-237 Instituto de Estudios Albacetenses. Albacete. 497 pp. Rodríguez de la Torre, F. (2010). El "enigma” de Toribio de Alcaraz. No hubo un arquitecto en América con tal nombre. Hubo dos. En Homenaje a Alfonso Santamaría Conde, 475-492. Instituto de Estudios Albacetenses. Albacete. 536 pp.

Sánchez-García, M. A. (2012). Sociedad, medicina e Ilustración en el mundo rural albacetense. Francisco Martínez Villascusa (1740-1793). Instituto de Estudios Albacetenses. Albacete. 269 pp.

Tobarra, M. (2019). El Instituto en los albores del siglo XIX (1900-1916). En: Los Instrumentos del Saber. El Instituto Histórico Bachiller Sabuco de Albacete. Catálogo de la Exposición.

Tomás-Ibáñez, A. (1993). Don Fructuoso Carpena Pellicer. En El archivo de la memoria. Disponible en: http://elarchivodelamemoria.com/ index.php/poesia/item/don-fructuoso-carpena-pellicer. (último acceso 23-05-2020)

Vila Valentí, J. (1989). El conocimiento geográfico de España. Geógrafos y obras geográficas. Editorial Síntesis. Madrid. 165 pp.

Vilar, P. (1964) Crecimiento y desarrollo. Economía e historia. Reflexiones sobre el caso español. Ediciones Ariel. Barcelona. 542 pp. 